\title{
GaN Quasi Z-Source DC/DC Converter for Electric Vehicles with Redox Flow Batteries
}

\author{
Pavel Skarolek, Jiř́ Lettl \\ Czech Technical University in Prague \\ Faculty of Electrical Engineering \\ Department of Electrical Drives and Traction, \\ Technicka 2, 16627 Prague 6, Czech Republic \\ skaropav@fel.cvut.cz, lettl@fel.cvut.cz
}

\begin{abstract}
Redox flow batteries mounted on the vehicle chassis behaves better at low voltage and high current while the tractive system of electric vehicles is more efficient at high voltage and low current. The proposed DC/DC converter provides the necessary tractive system isolation from the flow battery and keeps the voltage ratio while working in two quadrants of the current flow direction. The $\mathrm{Z}$-source converter topology enables the necessary wide range voltage control at high efficiency. The power density is increased using the Gallium Nitride $(\mathrm{GaN})$ transistors. The tested prototype of the converter proves that the topology is suitable for this application.
\end{abstract}

Keywords-GaN; Z-Source converter; DC/DC; redox flow battery

\section{INTRODUCTION}

The main trouble of electric vehicles is still the available energy density of the battery storage. According to studies [3] and [4] the redox flow battery can be used as a traction battery in a wide range of vehicles.

Flow batteries offer easily scalable solution as the energy is stored in tanks with electrolyte while the battery cells are relatively small compared to the stored energy [5]. Since the electrolyte is stored separately it is also possible to charge the battery simply by replacing the electrolyte. Both positive and negative electrolyte can be pumped out of the vehicle and charged separately for example in solar power plants where the flow batteries are starting to be used for the power output stabilization.

The complex system of flow batteries behaves better in case of low voltage and high current applications while the electric vehicle tractive system works better at high voltage and low current. To adapt these two systems together and to get benefits of both, the DC/DC converter was designed to achieve requirements of both systems.

The specific behavior of the flow battery is respected by the converter providing wide range voltage control. Flow batteries have usually bigger voltage difference between charged and discharged states. The Z-source converter topology [1] normally used in motor converters can be adapted to the DC/DC where it practically double the voltage control range at the given duty cycle ratio. The high duty cycle is important for the transformer with low voltage high current primary winding where it ensures high efficiency.

The behavior of the Z-source converter, the shootthrough time [2] fits the Gallium Nitride $(\mathrm{GaN})$ based semiconductors as they show better characteristics at high frequency hard switching compared to $\mathrm{Si}$ MOSFETs. As high power density devices are becoming available at reasonable price, the high efficient converters are beginning to be designed employing them.

\section{CONVERTER TOPOLOGY}

\section{A. Tractive System Topology}

The main benefit of the redox flow battery low voltage application is that the complex system including electrolyte tanks, pumps, valves and piping can be mounted on the vehicle chassis without the insulation.

The insulated high voltage tractive system will be behind the DC/DC converter, so the converter will provide the galvanic insulation. The tractive system topology example is shown in Figure 1.

\section{B. Technology of GaN Transistors}

Recently, the modern $\mathrm{GaN}$ transistors are becoming available in the field of power electronics and they are beginning to compete with $\mathrm{Si}$ and $\mathrm{SiC}$ semiconductors.

The main benefits are the reverse conduction region and linear output capacity change during turning-off [6]. GaN transistor has zero recovery charge as there is no freewheeling diode present, while the reverse current flows through the structure itself.

The linear output capacitance change during turning-off is causing constant $\mathrm{dV} / \mathrm{dt}$ slope which makes a better transistor performance at hard switching topology [6].

Figure 1. Tractive system topology

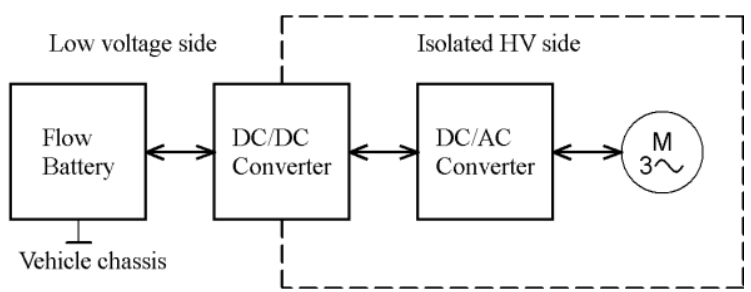




\section{Converter Topology Requirements}

To provide the isolation the converter must contain a transformer. To obtain high efficiency of the converter operation at low voltage and high current, the transformer copper losses has to be minimized.

The hard switching topology ensures the power transfer at the maximum possible duty cycle when the average current is equal to its effective value compared for example to the resonant topology that is more suitable for higher voltages and smaller currents.

Flow batteries need input voltage wide range control. To minimize the complexity and number of semiconductors the Z-source topology was chosen instead of for example uncontrolled DC/DC converter with separate chopper for voltage stabilization.

The converter must be bidirectional to enable regenerative braking of the electric vehicle. It means that both on primary and on secondary side must be active switching components, i.e. transistors.

\section{QUASI Z-SOURCE CONVERTER}

To fulfil the previously stated converter topology requirements the quasi Z-source topology (QZSI) has been chosen. The schematic diagram is shown in Figure 3.

The primary low voltage side on the left contains H-bridge inverter between the flow battery and the primary winding of the transformer. The secondary side is composed of similar H-bridge and QZSI stage.

For the following description of operation the QZSI stage can be divided into two buck converters; the first one with inductor L1 and filtration capacitor $\mathrm{C} 1$ and similarly the second one with L2 and C3.

In normal operation the primary side works as $\mathrm{H}$ bridge converter with given duty cycle $D$. The secondary side acts as a synchronous rectifier loaded into the QZSI stage.

Example of transistor switching timing for both primary and secondary side is shown in Figure 2.
Figure 2. Transistor switching for primary side duty cycle $\mathrm{D}=0.8$

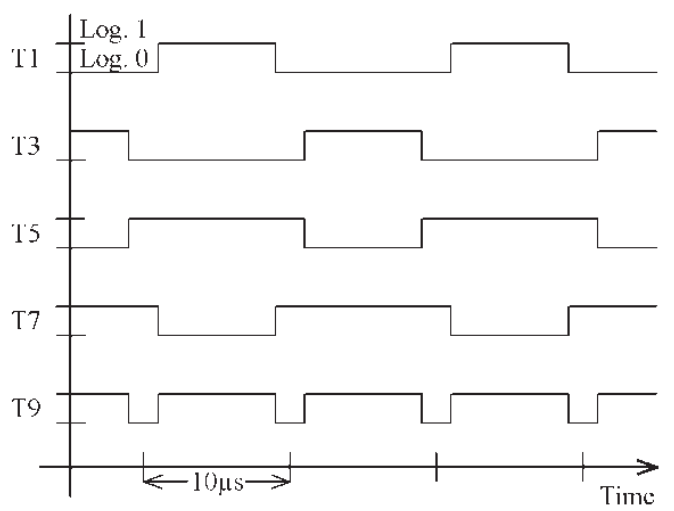

For duty cycle $D<1$ the secondary bridge operates in shoot-through state for the time $1-D$ while the T9 is turned-off.

The part of the circuit with L1 and $\mathrm{C} 1$ works as a regular buck converter. The voltage on $\mathrm{C} 1$ depends on the input voltage $U_{b a t}$ and on ratio $K$ of transformer turns.

$$
V_{C I}=K \cdot U_{b a t} \cdot D
$$

The transistor T9 is turned-on when the voltage is present across the $\mathrm{H}$-bridge, so the capacitor $\mathrm{C} 2$ is charged with the residual voltage that does not charged in $\mathrm{C} 1$.

$$
V_{C 2}=K \cdot U_{b a t} \cdot(1-D)
$$

The capacitor $\mathrm{C} 2$ connects the inductor $\mathrm{L} 2$ to the $\mathrm{H}$-bridge. It results in the second buck converter to operate with different voltage levels reduced by the charge on $\mathrm{C} 2$ resulting in the tractive system output voltage $V_{T S}$ on $\mathrm{C} 3$ being less than voltage on $\mathrm{C} 1$.

$$
V_{C 3}=V_{T S}=K \cdot U_{b a t} \cdot(2 D-1)
$$

Figure 3. Schematic diagram of the QZSI DC/DC converter

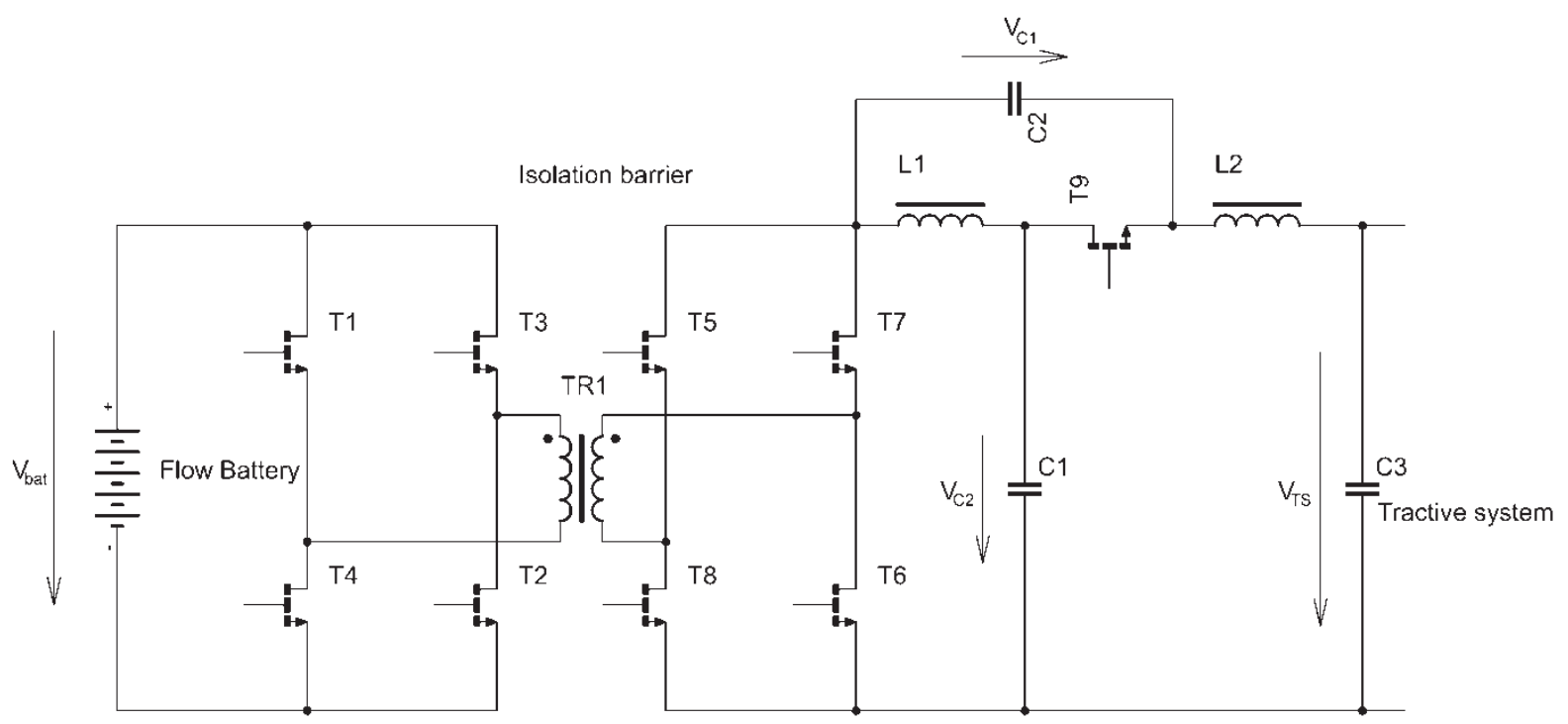


Figure 4. Comparison of the QZSI with classic buck-converter topology copper loss at the same input voltage range

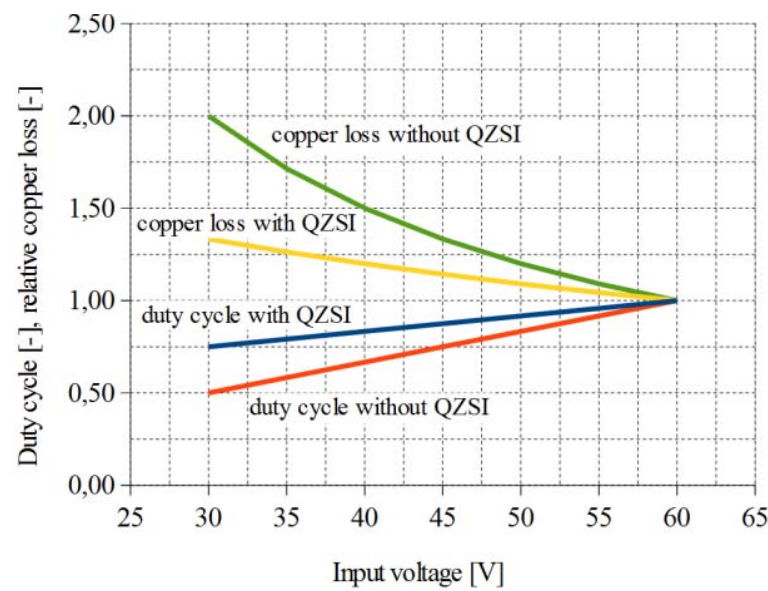

This topology is resulting in the double value of the output voltage in dependency on the transformer duty cycle. This results in lower copper loss in the whole control range of the converter. The comparison to the classic DC/DC converter with transformer and one inductor of the buck-converter is performed in Figure 4.

The reverse conduction resistance of $\mathrm{GaN}$ transistor depends on the gate charge. In case of the regular converter, it means that the dead-time setting has to be very precise using high resolution timers to achieve reasonable efficiency. In this topology, the secondary side shoot-through time [2] ensures the transistor driving in negative dead-time [10].

\section{PROTOTYPE MEASUREMENT RESUlTS}

Designed converter prototype of $3 \mathrm{~kW}$ was built using available $\mathrm{GaN}$ transistors GS61008P rated for $100 \mathrm{~V}, 80 \mathrm{~A}$ on the low voltage side and GS66508B $650 \mathrm{~V}, 30 \mathrm{~A}$ on the high voltage side. T9 is composed of parallel combination of two $650 \mathrm{~V} \mathrm{GaN}$ transistors.

The transformer has turns ratio 1:4 wound on ETD59 core, inductors L1, L2 are $150 \mu \mathrm{H}$ on toroidal sendust cores, capacitors $4.7 \mu \mathrm{F}$. The prototype is shown on the Figure 8.

The recently finished converter prototype was tested at low output power for the chosen transformer duty cycle $D=0.8$. The obtained voltage waveforms are recorded in following figures. From the presented waveforms the operation of the proposed topology of the bidirectional DC/DC converter with QZSI stage is obvious.

Figure 5 shows the voltage on the transformer secondary side that is measured on T8 Drain respectively to the minus pole of the supposed tractive system output.

The voltage waveform on T9 Source shows the rectified voltage shifted down by the $V_{C 2}$ value.

The output voltage $V_{T S}$ is reproduced in Figure 6 as a result of the waveform on T9 Source filtering. While the transformer duty cycle is 0.8 the output voltage $V_{T S}$ has value 0.6 of the rectified voltage on transformer secondary winding.
The transformer primary side voltage measured on T2 Drain is depicted in Figure 7 together with the secondary side voltage. The primary $\mathrm{H}$-bridge is turned-off while the secondary H-bridge is in the shoot-through state.

Figure 5. The transformer secondary side voltagemeasured on the T8 and rectified voltage on T9 Source.

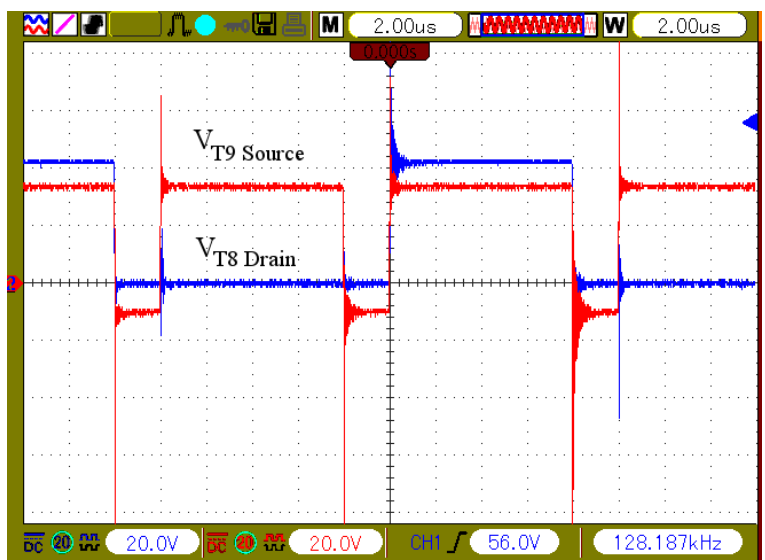

Figure 6. Output voltage $V_{T S}$ waveform as a result of the T9 Source voltage filtering.

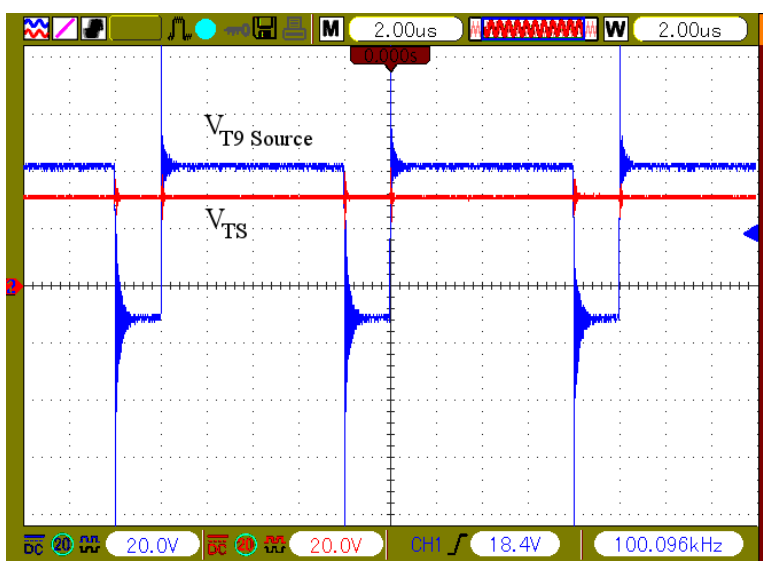

Figure 7. Voltage on the primary side of the transformer together with the T9 Source voltage.

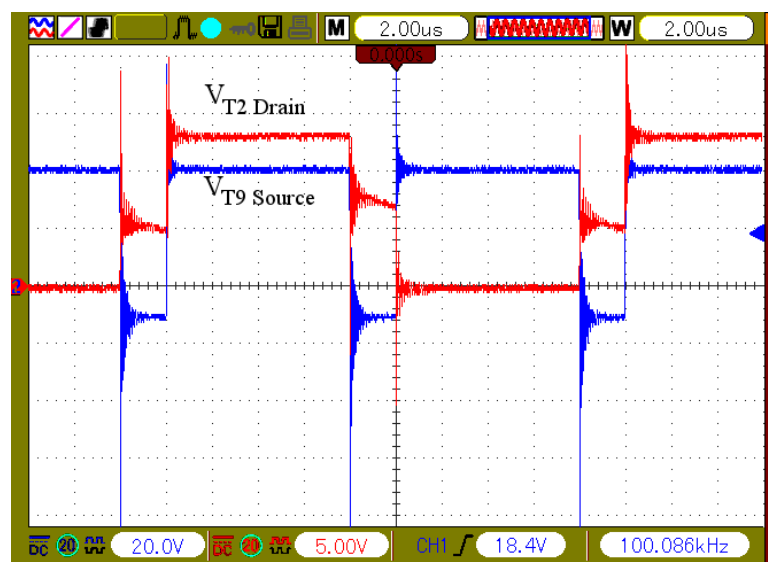


Figure 8. The converter prototype

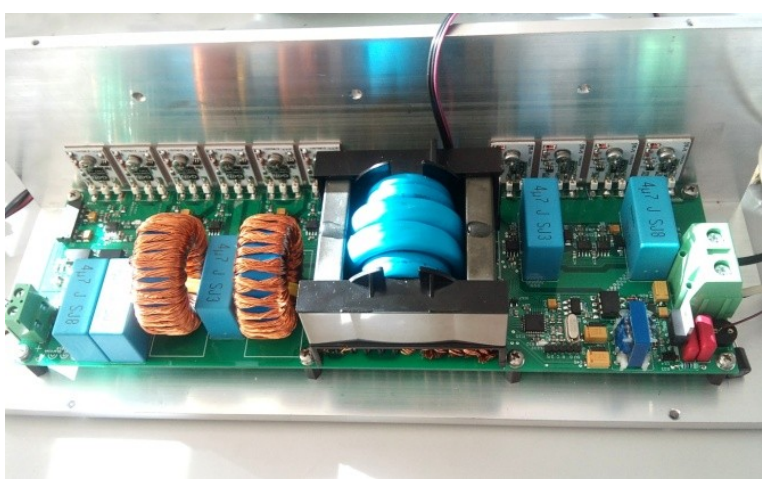

V. FUTURE WORK

The transformer design needs to be improved because the minimum leakage inductance is required for this converter topology. Transistors can operate on frequency high enough and the planar transformer can be designed. Since the designed prototype power is too small for electric vehicle, a higher one has to be made and multiple of them should be connected in parallel to divide the current between them.

\section{CONCLUSION}

The prototype of the DC/DC converter with QZSI stage was successfully tested and the obtained results prove that the topology provides the expected voltage control while the high duty cycle on the transformer is kept to minimize copper losses. The QZSI stage enables the secondary H-bridge to operate with negative dead-time which ensures low losses in the reverse conduction region of $\mathrm{GaN}$ transistors.

GaN transistors can operate the converter at high frequency which leads to smaller inductors. It means that high power density and efficiency can be achieved.

\section{ACKNOWLEDGMENT}

This work is supported by the Technology Agency of the Czech Republic under the grant for Competence Centre Programme project No. TE02000103 and by the Student Grant Agency of the Czech Technical
University in Prague under the grant No. SGS17/180/OHK3/3T/13.

\section{REFERENCES}

[1] O. ELLABBAN, J. VAN MIERLO AND P. LATAIRE, "Direct torque controlled space vector modulated induction motor fed by a Z-source inverter for electric vehicles," 2011 International Conference on Power Engineering, Energy and Electrical Drives, Malaga, 2011, pp. 1-7.

[2] A. S. KIRAN AND RAGAVAN K., "Direct Torque Control using switching table for induction motor fed by Quasi ZSource Inverter," 2016 IEEE 1st International Conference on Power Electronics, Intelligent Control and Energy Systems (ICPEICES), Delhi, 2016, pp. 1-5.

[3] J. CAMPILLO, N. GHAVIHA, N. ZIMMERMAN AND E. DAHLQUIST, "Flow batteries use potential in heavy vehicles," 2015 International Conference on Electrical Systems for Aircraft, Railway, Ship Propulsion and Road Vehicles (ESARS), Aachen, 2015, pp. 1-6.

[4] M. R. MOHAMED, S. M. SHARKH AND F. C. WALSH, "Redox flow batteries for hybrid electric vehicles: Progress and challenges," 2009 IEEE Vehicle Power and Propulsion Conference, Dearborn, MI, 2009, pp. 551-557.

[5] M. GUARNIERI, P. MATTAVELLI, G. PETRONE AND G. SPAGNUOLO, "Vanadium Redox Flow Batteries: Potentials and Challenges of an Emerging Storage Technology," in IEEE Industrial Electronics Magazine, vol. 10, no. 4, pp. 2031, Dec. 2016.

[6] G. DEBOY, M. TREU, O. HAEBERLEN AND D. NEUMAYR, "Si, SiC and GaN power devices: An unbiased view on key performance indicators," 2016 IEEE International Electron Devices Meeting (IEDM), San Francisco, CA, USA, 2016, pp. 20.2.1-20.2.4.

[7] X. HUANG, T. LIU, B. LI, F. C. LEE AND Q. LI, "Evaluation and applications of $600 \mathrm{~V} / 650 \mathrm{~V}$ enhancementmode GaN devices," 2015 IEEE 3rd Workshop on Wide Bandgap Power Devices and Applications (WiPDA), Blacksburg, VA, 2015, pp. 113-118.

[8] GaN Systems, "Bottom-side cooled $650 \mathrm{~V}$ E-mode GaN transistor," GS66508B Premiliary Datasheet, 2016.

[9] IXYS, "9-Ampere Low-Side Ultrafast MOSFET Drivers," IXDD609SI Datasheet, September 2016.

[10] R. Xie, H. Wang, G. Tang, X. Yang and K. J. Chen, "An Analytical Model for False Turn-On Evaluation of HighVoltage Enhancement-Mode GaN Transistor in Bridge-Leg Configuration," in IEEE Transactions on Power Electronics, vol. 32, no. 8, pp. 6416-6433, Aug. 2017 